\title{
Radial artery access for neuroendovascular procedures: safety review and complications
}

\author{
Kazim H Narsinh (1) , ${ }^{1}$ Mohammed H Mirza 이, ${ }^{2}$ M Travis Caton Jr, ${ }^{1}$ Amanda Baker, ${ }^{1}$ \\ Ethan Winkler, ${ }^{3}$ Randall T Higashida, ${ }^{1}$ Van V Halbach, ${ }^{1}$ Matthew R Amans (ㄷ, ${ }^{1}$ \\ Daniel L Cooke, ${ }^{1}$ Steven W Hetts $10,{ }^{1}$ Adib A Abla, ${ }^{3}$ Christopher F Dowd ${ }^{1}$
}

${ }^{1}$ Radiology \& Biomedical Imaging, University California San Francisco, San Francisco, California, USA

${ }^{2}$ Radiology, University of Illinois College of Medicine at Peoria, Peoria, Illinois, USA

${ }^{3}$ Neurological Surgery, University California San Francisco, San

Francisco, California, USA

\section{Correspondence to}

Dr Kazim H Narsinh, University

California San Francisco, San

Francisco, CA 94143, USA;

kazim.narsinh@ucsf.edu

Received 4 February 2021 Accepted 16 June 2021

Published Online First

22 September 2021

\section{Linked}

- http://dx.doi.org/10.1136/ neurintsurg-2021-017871

Check for updates

(C) Author(s) (or their employer(s)) 2021. No commercial re-use. See rights and permissions. Published by BMJ.

To cite: Narsinh $\mathrm{KH}$

Mirza MH, Caton Jr MT, et al.

$J$ Neurolntervent Surg

2021:13:1132-1138.

\section{ABSTRACT}

Although enthusiasm for transradial access for neurointerventional procedures has grown, a unique set of considerations bear emphasis to preserve safety and minimize complications. In the first part of this review series, we reviewed anatomical considerations for safe and easy neuroendovascular procedures from a transradial approach. In this second part of the review series, we aim to (1) summarize evidence for safety of the transradial approach, and (2) explain complications and their management.

\section{INTRODUCTION}

Interest has burgeoned in the use of the radial artery as an access site for neurointerventional procedures because it has been associated with fewer complications, shorter hospital stays, and patient preference. Nevertheless, transradial access (TRA) presents a unique set of considerations to preserve safety, including knowledge of the anatomical variations of the upper extremity arterial supply, access site complications, and closure techniques. Herein, we aim to review radial artery access for neuroendovascular procedures with attention to (1) a literature review of the evidence for safety in neurointervention, and (2) complications and their management.

Literature in interventional cardiology has substantiated certain advantages of the TRA route in the setting of coronary angiography and intervention. Compared with the transfemoral access (TFA) route, TRA has been associated with significantly reduced all-cause mortality, major cardiovascular events, all forms of bleeding, length of hospital stay, and vascular and access site complications (eg, hematoma, pseudoaneurysm, arteriovenous fistula, need for vascular repair). These findings are evidenced by randomized controlled trials, systematic reviews, and meta-analyses cumulatively covering $>35$ studies and $>28000$ participants. ${ }^{1}$ Of note, however, these studies do not uniformly make use of ultrasound guidance with both access routes, some report slightly lower procedural success rates with TRA, and crossover from TRA to TFA is not infrequent. ${ }^{2}$ However, a lower complication rate and risk of stroke has been consistently demonstrated with TRA in interventional cardiology, without a difference in contrast media use, procedure duration, fluoroscopy, and door-to-balloon time for ST elevation myocardial infarction (STEMI). As a result, the American Heart Association and European Society of Cardiology recommend a 'radial first' strategy for arterial access, particularly in the setting of acute coronary syndromes and myocardial infarction. ${ }^{13}$ This paves the way for interventional neuroradiology/neurointerventional surgery to adopt an alternative access site for other endovascular procedures, although it has yet to be substantiated by the degree of evidence that has supported interventional cardiology's transition.

\section{RADIAL ARTERY ACCESS SAFETY FOR NEUROENDOVASCULAR PROCEDURES Methods}

Literature search

We performed a literature search through MEDLINE/PubMed and Ovid for papers published in the English literature from 2018 to 2021 using the following search parameters: ((radial[Title]) OR (transradial[Title])) AND (('Journal of neurointerventional surgery'[Journal]) OR (neurointerventions) OR (neuroendovascular)).

Studies measuring both crossover and access site complication rates as outcomes in patients $(n>100)$ undergoing a neuroendovascular procedure (diagnostic or interventional) with a radial-first approach were included. Exclusion criteria were: (1) case reports/series or studies with $\mathrm{n} \leq 100$ subjects; (2) studies not reporting either one of the two outcomes of interest; (3) studies published before 2018 (when available wires/catheters/sheaths were more limited); (4) studies not adopting a radial-first approach; and (5) studies not involving neuroendovascular procedures.

\section{Outcome variables}

The following TRA outcomes were studied: access site complication rate, overall complication rate, and rate of crossover defined as any conversion from the originally intended access site. Single-arm studies were separated from comparative studies. In the case of comparative studies, the same three outcomes were measured for transfemoral comparison.

\section{RESULTS}

A total of 95 unique articles were retrieved after the first round of research, 69 of which were excluded by title and abstract screening. The full texts of the 


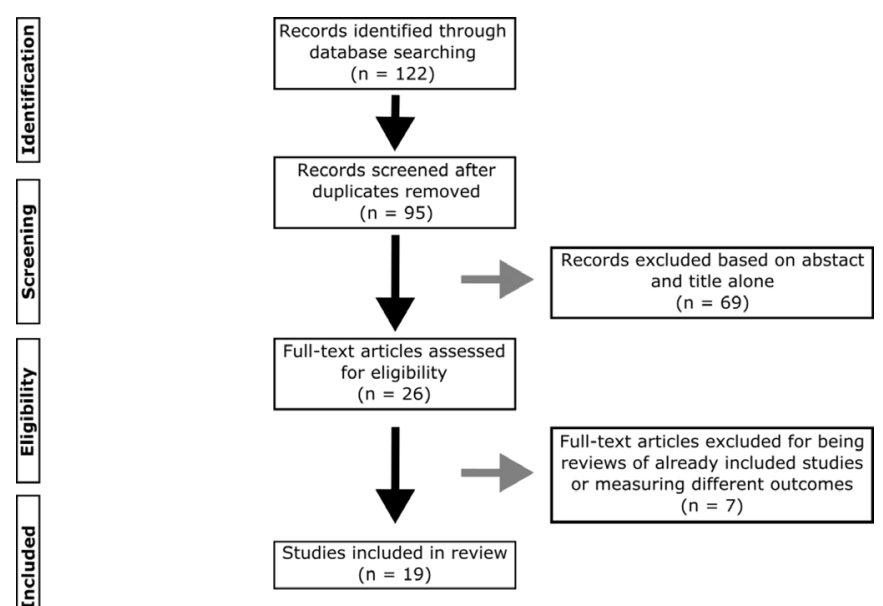

Figure 1 PRISMA flow diagram. PRISMA, Preferred Reporting Items for Systematic Reviews and Meta-Analyses.

remaining 26 articles were accessed, and 19 articles matching the inclusion criteria were included: 13 single-arm studies and six comparative studies. Fourteen studies were retrospective cohort, four prospective cohort, and one systematic review and metaanalysis (figure 1).

All neurointerventional studies of TRA suffer from a lack of randomization (tables 1 and 2), which introduces patient selection bias, except for one recent small study which assigned access site based on the day of presentation. ${ }^{4}$ A recent single arm study of 121 patients who underwent diagnostic and interventional neuroendovascular procedures after adoption of a 'radial-first' approach at a single institution had a transfemoral crossover rate of about $25 \%,{ }^{5}$ while an older retrospective study of 49 patients undergoing transradial flow diversion had a transfemoral crossover rate of about $20 \%{ }^{6}$ In contrast, crossover rates in nonrandomized neurointerventional cases are significantly lower, approaching approximately $5 \% .^{7}$ These data suggest that patient selection bias has strongly affected the complication rates of most prior studies of TRA (tables 1 and 2). Randomized controlled clinical trials are needed to establish that TRA has a decreased complication rate relative to TFA for neuroendovascular procedures, although current non-randomized studies suggest that the complication rate may be lower for selected patients.

\section{COMPLICATIONS OF TRA}

Common complications of transradial procedures include radial artery spasm (further complicated by catheter entrapment and radial artery eversion), radial artery occlusion (further complicated by hand ischemia), and radial artery perforation (further complicated by forearm hematoma and compartment syndrome). Rare complications include radial artery pseudoaneurysm, granuloma or sterile abscess formation, and arteriovenous fistula formation. Below we provide a more detailed discussion of the former three conditions that arise more frequently (and their associated sequelae), followed by the latter three rare complications.

\section{Radial artery spasm}

The radial artery is a muscular artery rich in $\alpha-1$ receptors, making it highly spasmodic compared with other vessels. ${ }^{8}$ Thus, radial artery spasm causes a significant reduction in lumen diameter. This can be prevented by using intra-arterial 'cocktails' that include heparin, nitroglycerine, and verapamil diluted in normal saline. They induce rapid, prolonged radial artery vasodilatation and reduce vasospasm during transradial procedures. ${ }^{9-11}$ Preprocedural administration of a combined topical gel of verapamilnitroglycerine-lidocaine can also significantly increase the size of the radial artery and reduce pain during puncture. ${ }^{12}$ The incidence of radial artery spasm can also be decreased by use of a long $23 \mathrm{~cm}$ hydrophilic sheath because they protect the full length of the radial artery and diminish repetitive friction forces of the catheter against the vessel wall. ${ }^{13}$ Although prevention of radial artery spasm is the preferred approach, once radial artery spasm has been detected, several techniques can be used to relieve spasm including forearm heating with forearm compresses, deepening of sedation or induction of general anesthesia, and administering additional intra-arterial vasodilators. ${ }^{14} \mathrm{~A}$ small randomized controlled trial (RCT) $(n=20)$ showed power injecting normal saline through the sheath $(10 \mathrm{~mL} / \mathrm{s}$ for $10 \mathrm{~mL})$ to induce pressure-mediated vasodilation induces greater radial artery intraluminal diameter acute gain when compared with intra-arterial administration of a combination of nitroglycerin and verapamil, while causing significantly less reduction in blood pressure. ${ }^{15}$ Another small RCT $(n=99)$ demonstrated inflating a blood-pressure cuff above systolic blood pressure for $5 \mathrm{~min}$ before rapid deflation to induce flow-mediated vasodilation leads to similar median time to return of radial pulse-compared with sublingual nitroglycerin-with less prevalence of headache and decreased blood pressure. ${ }^{16}$ Isolated cases have also been reported wherein administering a radial nerve or brachial plexus anesthetic block under ultrasound guidance with the help of an anesthesiologist as a rescue measure provides a pharmacologic sympathectomy once many of the aforementioned methods have failed. ${ }^{17} 18$

\section{Catheter entrapment}

Severe radial artery spasm, worsened by excessive catheter manipulation or kinking or radial artery tortuosity, can lead to catheter entrapment. Any kinks in catheters should be untied slowly and carefully by rotating in the reverse direction or by introducing guidewires within catheters. Any fragments of catheters retained within the arterial system may lead to hand ischemia, thrombus formation, or infection.

\section{Radial artery eversion}

Radial artery eversion (figure 2) is an extremely rare complication caused by severe radial artery spasm, which may prevent catheter and sheath removal. As above, when encountering severe radial artery spasm, analgesia, vasodilators, deep sedation or even general anesthesia are administered. While these measures are usually successful, instruments must never be forcefully extracted, and careful attention to preventing or treating radial artery spasm is the preferred approach. ${ }^{13} 19$

\section{Radial artery occlusion}

Radial artery occlusion is a common complication of transradial catheterization, with most operating physicians underestimating its incidence. It occurs at an incidence of $7.7 \%$ within 24 hours, declining to $5.5 \%$ at 1 month due to spontaneous recanalization. ${ }^{20}$ Radial artery occlusion has been associated with larger sheath sizes, smaller radial arteries, and diabetes mellitus. ${ }^{21-23}$ Other predictors such as patient age, body habitus, procedure duration, and hemostasis duration have shown inconsistent findings among different clinical studies. Radial artery occlusion proximal to the anatomic snuffbox can be decreased by accessing 


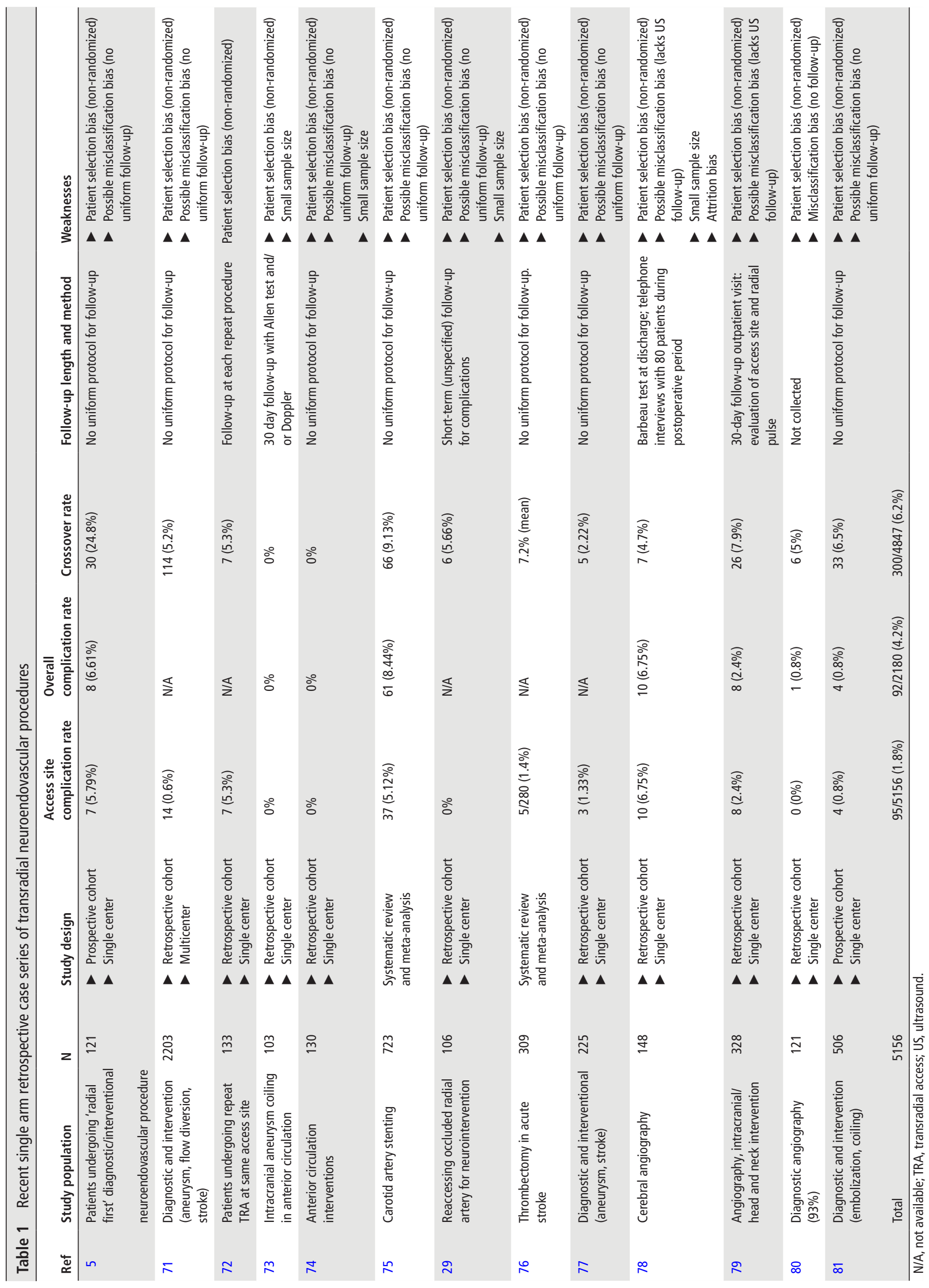




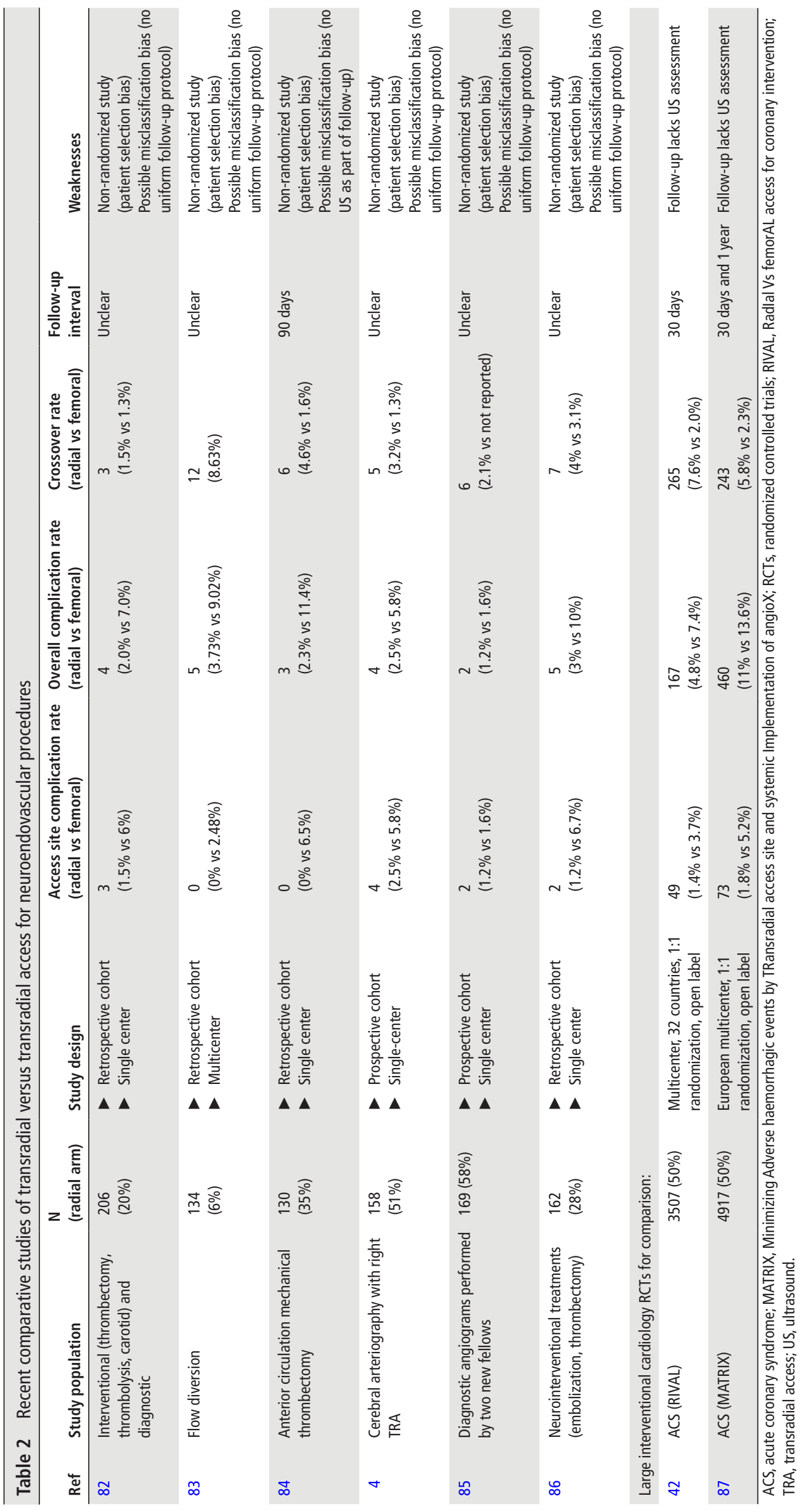




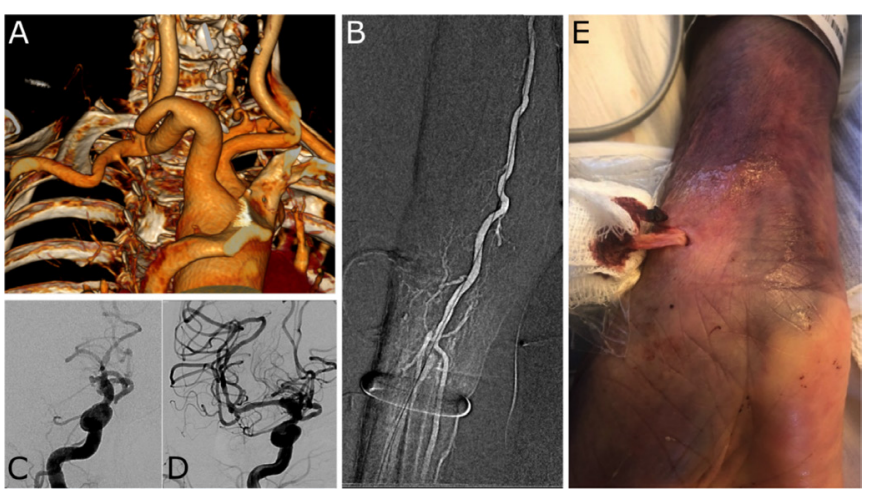

Figure 2 Radial artery eversion. (A) Three dimensional volume rendered reformat of neck $\mathrm{CT}$ angiography in right anterior oblique projection shows tortuous proximal right common carotid artery in an elderly patient with a type 3 aortic arch and acute ischemic stroke due to large vessel occlusion. (B) Right radial access was obtained for mechanical thrombectomy. After thrombectomy, the right radial access sheath was replaced with an arterial line. (C) Right internal carotid arteriogram in left anterior oblique Townes projection shows occlusion of the right middle cerebral artery. (D) After mechanical thrombectomy, right internal carotid arteriogram shows recanalization of the right middle cerebral artery. (E) After removal of the right radial artery line on day 1 after thrombectomy, eversion of the right radial artery was seen.

the distal radial artery in the anatomic snuffbox distal to the origin of the superficial palmar branch. ${ }^{24}$

Due to the dual blood supply of the hand from radial and ulnar arteries to the palmar arch, radial artery occlusion is usually a benign condition that is most often asymptomatic. Although usually benign, radial artery occlusion should be avoided for three reasons. First, radial artery occlusion prevents the future use of the radial artery as a conduit for coronary artery bypass grafting, extracranial-intracranial bypass grafting, or arteriovenous fistula creation for hemodialysis access. ${ }^{25-28}$ Second, radial artery occlusion makes future ipsilateral transradial interventions more difficult. A recent single arm study of 106 patients undergoing repeat TRA for neuroendovascular procedures showed a $94.3 \%$ success sion. ${ }^{29}$ Cases in which repeat ipsilateral TRA is complicated by radial artery occlusion either warrants crossover to an alternative access site or requires recanalization. Recanalization can be carried out via the anatomical snuffbox or retrograde with the aid of a balloon back up. However, this extra procedure carries with it additional risks of other access site complications such as dissection and hematoma. ${ }^{30-32}$ Lastly, radial artery occlusion can be symptomatic, resulting in paresthesia (1.52-1.61\%), pain at the site of puncture or occlusion (6.67-7.77\%), or reduced hand/digit motor function $(0.26-0.49 \%))^{33} 34$ Some of these complaints may be self-limiting, but there is currently inadequate follow-up data to estimate the duration of symptoms accurately (table 1). Also, in rare cases, radial artery occlusion progresses to critical ischemia of the hand. ${ }^{33} 34$

The majority of operating physicians do not routinely check for radial artery occlusion before hospital discharge, while the majority of those who do rely on clinical assessment of the radial pulse. ${ }^{35}$ We recommend diagnosing radial artery occlusion objectively using ultrasound rather than depending on the clinical diagnosis of an absent radial pulse, as assessment by palpation alone underestimates the true incidence of radial artery occlusion. rate, but five of the six failures were due to radial artery occlu-

Some measures to decrease the risk of radial artery occlusion include higher intra-arterial heparin doses ( $\geq 5000 \mathrm{IU})$, shorter compression times ( $\leq 15 \mathrm{~min}$ ), and patent hemostasis defined as hemostasis with enough pressure applied to the vessel to avoid bleeding but not enough to prevent blood flow. ${ }^{2036} 37$ Patent hemostasis technique should ensure radial artery patency during closure with a reverse Barbeau's test. ${ }^{38}$ Another technique to reduce radial artery occlusion is ipsilateral ulnar artery compression during hemostasis, which increases radial artery flow, and can be used simply and effectively for reducing the risk of radial artery occlusion after transradial catheterization. ${ }^{39} 40$

\section{Hand ischemia}

Hand ischemia rarely presents as a complication of radial artery occlusion due to the dual blood supply of the hand and an extensive network of collaterals. In fact, some suggest that pre-procedural examination for a complete palmar arch using Barbeau's test may not be necessary because it is not predictive of ischemic complications. ${ }^{354}$ The RIVAL (RadIal Vs femorAL access for coronary intervention) RCT comparing TFA and TRA in acute coronary syndrome patients undergoing percutaneous coronary intervention showed a $0.2 \%$ rate of symptomatic radial artery occlusion requiring medical attention. ${ }^{42}$ Raynaud's disease puts patients at higher risk of hand ischemia and is a contraindication to TRA. ${ }^{1}$ Management of hand ischemia is mainly conservative with possible short-term use of aggressive anticoagulation, with a success rate of $87 \% .{ }^{43}$ Percutaneous and surgical management have been described in cases of acute limbthreatening ischemia (figure 3$).^{44} 45$

\section{Radial artery access closure}

Prevention of radial artery occlusion and hand ischemia can be achieved through use of the smallest possible sheath size, intraarterial vasodilators and heparin, as well as proper attention to closure technique. Following TRA, several techniques are available to achieve hemostasis of the radial artery including manual compression, mechanical compression, and hemostatic agents.

Manual compression remains a viable option for achieving hemostasis, especially in diagnostic catheterizations with short durations. The superficial course of the radial artery makes manual compression easily achievable with two to three fingers and intermittent ulnar artery compression every 2 min. Pulse oximetry is monitored to ensure adequate perfusion without compromising hemostasis, and pressure over the radial artery is decreased in case of absent antegrade flow waveforms. Manual compression can be more effective than mechanical compression in performing patent hemostasis without any difference in the incidence of radial artery occlusion, and also achieves hemostasis in a shorter duration (14-22 min vs 2-3 hours) and at a lower cost than mechanical compression. ${ }^{46-48}$ Despite its advantages, manual compression is not widely adopted as first line because it usually demands prolonged post-procedural involvement of the interventional team.

Mechanical compression has historically used a balloon compression bracelet typified by the TR Band (Terumo Medical, Tokyo) with similar iterations including the VascBand (Teleflex, Wayne, PA), Tracelet (Medtronic, Dublin, Ireland), Safeguard Radial (Merit, South Jordan, UT), and Zephyr (Cordis, Miami Lakes, FL). The bracelet is applied at the arterial puncture site, then the bladder inflated, and the radial sheath is removed from under the band. The bladder is then decompressed until some mild bleeding occurs, and then the bladder is re-inflated with $1-2 \mathrm{~mL}$ of air. Then, antegrade radial artery flow is confirmed with a reverse Barbeau test (compression of the ulnar artery 


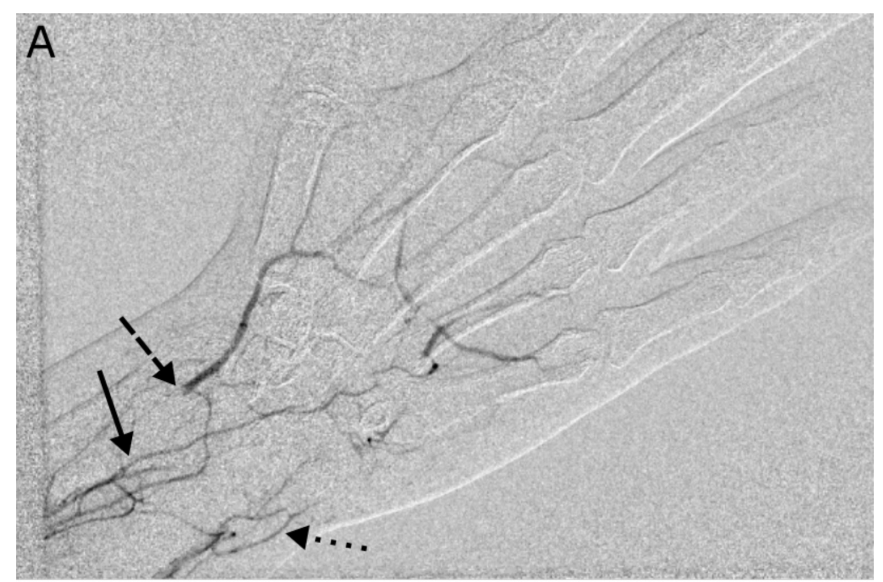

B

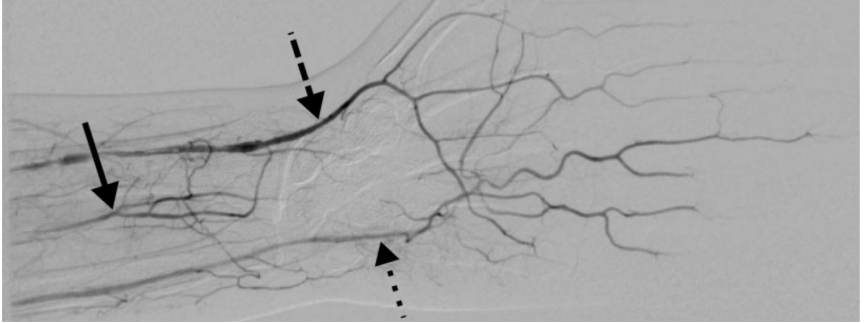

Figure 3 Hand ischemia. (A) Radial artery occlusion (dashed arrow) with distal flow supplied by the palmar carpal branch of the interosseous artery (solid arrow) in an adult patient on day 1 after transradial access who presented with significant wrist pain and fourth digit paresthesias with pallor on exam. Note the ulnar artery filling defects (dotted arrow) despite the patient's pre-procedural Barbeau type A waveform. (B) Follow-up angiogram after both radial and ulnar intra-arterial tPA lysis demonstrates marked improvement in both radial (dashed arrow) and ulnar (dotted arrow) artery flow with minimal reliance of collateral supply from the interosseous artery (solid arrow). tPA, tissue plasminogen activator.

with observation of the plethysmography waveform to ensure 'patent hemostasis'); $3 \mathrm{~mL}$ of air is withdrawn from the bracelet after $30 \mathrm{~min}$, then an additional $3 \mathrm{~mL}$ every $15 \mathrm{~min}$. If bleeding occurs, the removed air is re-introduced. There is no significant difference in bleeding between mechanical and manual compression. ${ }^{46}$ However, compared with pressure dressings, mechanical compression reduces hemostasis duration, radial artery occlusion incidence, puncture site oozing, and patient discomfort. ${ }^{49}$

Gauze pads impregnated with a hemostatic agent such as kaolin (QuickClot Radial, Teleflex, Wayne, PA), chitosan (ChitoClot, Anscare, Taiwan), or potassium ferrate (StatSeal, Biolife, Sarasota, FL) can lead to shorter hemostasis durations. ${ }^{50-52}$ Kaolin activates factor XII, initiating the coagulation cascade, while chitosan attracts platelets, promoting platelet plug formation. Such agents are applied tightly at the puncture site with the sheath still in place. The sheath is then removed, and a small amount of blood is allowed to come into contact with the gauze activating the hemostatic agent. Manual pressure is applied to the gauze for $5 \mathrm{~min}$, and then an elastic band is used to apply pressure for an additional 25-55 min. Compared with mechanical compression with the TR Band, hemostatic agents usually achieve hemostasis in significantly less time (30-60 min versus $\sim 150 \mathrm{~min}$ ). In addition, chitosan-based hemostatic pads have demonstrated a lower incidence of radial artery occlusion at 24 hours when compared with the TR Band. ${ }^{53}$ Furthermore, adding chitosan-based hemostatic pads to both mechanical compression devices (TR Band, rotary compression device) significantly reduces hemostasis duration with no difference in vascular complications. $^{5154}$

Some hemostasis techniques achieve significantly shorter hemostasis times, such as use of the VasoStat (Forge Medical, Bethlehem, PA), a focused compression device, ${ }^{55-57}$ or hemostatic agent compression pads. All methods ensuring patent hemostasis are associated with significantly less radial artery occlusion. No single method, however, has been shown to be superior for preventing complications such as radial artery occlusion. We recommend practitioners follow local preferences according to available resources, as concrete evidence favoring one method over another is still lacking. ${ }^{58}$

\section{Radial artery perforation}

Radial artery perforation is a rare complication of TRA with a $0.1-1 \%$ incidence. Risk factors include female sex, old age, short stature, hypertension, excess tortuosity, excessive anticoagulation, anomalous radial artery, and excessive guidewire or catheter manipulation. ${ }^{5960}$ Radial artery perforation should be suspected in case of resistance to guidewire advancement or intraprocedural pain at the perforation site. It may progress to forearm hematoma and compartment syndrome if not detected and managed promptly with prolonged extrinsic compression or internal tamponade. ${ }^{61}$

\section{Forearm hematoma}

Hematoma formation at the site of radial puncture or in the forearm is an uncommon and usually benign condition. Forearm hematomas are classified into four grades: grade 1 (local, superficial) $<5 \mathrm{~cm}$, grade 2 (moderate muscular infiltration) $<10 \mathrm{~cm}$, grade 3 reaches distal to the elbow, and grade 4 extends proximal to the elbow. The incidence of grade 1 is $<5 \%$, grade 2 $<3 \%$, grade $3<2 \%$, and grade $4<0.1 \%$. $^{62}$ Forearm hematomas are associated with radial artery occlusion, significant access site bleeding, improper hemostasis, radial artery perforation, use of non-coated sheaths, and female sex.

Asymptomatic, non-expanding forearm hematomas are managed conservatively with observation, elevation, and compression. Early detection is key and reversal of anticoagulation (eg, using protamine) should be considered. Grade 1 and 2 hematomas are managed with analgesia, additional compression, and local ice, while grade 3 and 4 hematomas may benefit from blood pressure cuffs inflated to $20 \mathrm{mmHg}$ less than systolic blood pressure and deflated every $15 \mathrm{~min}$ with pulse oximetry monitoring. ${ }^{4} 62$

An expanding hematoma or one causing neurovascular compromise must be urgently examined to confirm patency of both radial and ulnar arteries, evaluate digital perfusion, and measure compartment pressures. Forearm hematomas rarely progress to compartment syndrome requiring surgical hematoma evacuation. ${ }^{36}$

\section{Compartment syndrome}

Forearm compartment syndrome is a rare but devastating complication following TRA. The etiology is the same as for forearm hematomas, with some authors considering it a grade 5 hematoma, and has been associated with female sex and low body surface area. ${ }^{6364}$

Normal compartment pressures in the forearm are $<10 \mathrm{mmHg}$, with an increase to $>30 \mathrm{mmHg}$ considered diagnostic of acute compartment syndrome. However, the diagnosis should rather be 
based on clinical presentation that can be quite rapid with acute forearm swelling, pallor, and pain following the procedure that can further progress to ischemia of the muscles and nerves, with disability and contracture if not managed in a timely fashion. ${ }^{63-65}$

Prevention involves objectively examining blood flow to the palmar arch before the procedure, using an appropriate anticoagulant dose, and proper management of intraprocedural tortuosity and radial artery spasm. After the procedure, the hemostatic device and puncture site should be continuously checked. ${ }^{44} 63$

Management includes inflation of a blood pressure cuff at the site of pain or swelling at $15-20 \mathrm{mmHg}$ below systolic blood pressure to ensure distal flow confirmed by pulse oximetry for $15 \mathrm{~min}$ and repeated twice on average. Blood pressure should also be tightly controlled with anticoagulation reversal or discontinuation. Most cases respond to conservative management, but surgical fasciotomy may occasionally be required. ${ }^{446365}$

\section{Radial artery pseudoaneurysm}

Radial artery pseudoaneurysm is a very rare complication following TRA with an incidence rate of $0.03 \% .{ }^{66}$ Presentation is within days to weeks as localized, pulsating swelling that may be painful. Diagnosis is confirmed by Doppler ultrasound or angiography. Radial artery pseudoaneurysm can be caused by excessive anticoagulation, anomalous radial artery perforation, excessive puncture attempts, and inadequate compression hemostasis. ${ }^{67}$

Management can be escalated sequentially from firm compression to ultrasound-guided compression of the pseudoaneurysm neck to ultrasound-guided thrombin injection. Surgery is indicated in rare cases of infection, compressive ischemic symptoms, or failure of non-surgical management.

\section{Granuloma and sterile abscess formation}

Granuloma and sterile abscess formation are rare, self-liming complications induced by a reaction to introducer sheath coating that can be stripped off and retained within the skin. Of note, the Cook vascular sheaths implicated in causing granulomas are no longer in use. ${ }^{68}$ They form within 2-3 weeks as a tender mass near the puncture site. Due to its late presentation, patients present to their primary care physician rather than their interventionalist, frequently leading to its misdiagnosis as a radial artery pseudoaneurysm. Thus, Doppler ultrasound is important to confirm diagnosis and avoid unnecessary intervention. ${ }^{69}$

Management is limited to observation. Antibiotics are not indicated in the absence of fever and leukocytosis. Acute granulomas resolve within weeks and chronic granulomas within months. Wiping the vascular sheath with damp gauze before insertion may remove excess hydrophilic material and reduce the incidence of granulomas.

\section{Arteriovenous fistula}

Arteriovenous fistulae rarely present as a complication-with an incidence $<0.03 \%$ - due to the lack of large veins near the radial artery. It presents as a mass or palpable thrill near the puncture site, and Doppler ultrasound confirms the diagnosis. Management may be conservative with prolonged compression, interventional using covered stents, or surgical repair. ${ }^{1470}$

\section{CONCLUSION}

The radial artery provides an alternative-and in some ways more favorable- access site for the neurointerventionalist. Nonetheless, it demands the physician be well versed in identifying anatomical variants, weighing the risks and benefits of different closure techniques, and recognizing access site complications.
While the advantages of transradial over transfemoral catheterization has been established in the field of interventional cardiology with randomized controlled clinical trials, further study is warranted to directly establish its advantage in specific realms of interventional neuroradiology/neurointerventional surgery.

Contributors KHN wrote the manuscript and supervised the review. MHM performed the literature review and analysis and provided with figures. MTC, $A B$, EAW, RTH, VVH, MRA, DLC, SWH, AAA, CFD provided edits to the manuscript.

Funding KHN was supported by NIH NINDS U54 NS065705.

Competing interests None declared.

Patient consent for publication Not required.

Provenance and peer review Commissioned; externally peer reviewed.

\section{ORCID iDs}

Kazim H Narsinh http://orcid.org/0000-0002-2019-5461

Mohammed H Mirza http://orcid.org/0000-0003-3784-5894

Matthew R Amans http://orcid.org/0000-0002-8209-0534

Steven W Hetts http://orcid.org/0000-0001-5885-7259

\section{REFERENCES}

1 Mason PJ, Shah B, Tamis-Holland JE, et al. An update on radial artery access and best practices for transradial coronary angiography and intervention in acute coronary syndrome: a scientific statement from the American Heart Association. Circ Cardiovasc Interv 2018;11:e000035.

2 Kolkailah AA, Alreshq RS, Muhammed AM, et al. Transradial versus transfemoral approach for diagnostic coronary angiography and percutaneous coronary intervention in people with coronary artery disease. Cochrane Database Syst Rev 2018:4:CD012318.

3 Neumann F-J, Sousa-Uva M, Ahlsson A, et al. 2018 ESC/EACTS guidelines on myocardial revascularization. Eur Heart J 2019:40:87-165.

4 Stone JG, Zussman BM, Tonetti DA, et al. Transradial versus transfemoral approaches for diagnostic cerebral angiography: a prospective, single-center, non-inferiority comparative effectiveness study. J Neurointerv Surg 2020;12:993-8.

5 Almallouhi E, Leary J, Wessell J, et al. Fast-track incorporation of the transradial approach in endovascular neurointervention. J Neurointerv Surg 2020;12:176-80.

6 Chen SH, Snelling BM, Shah SS, et al. Transradial approach for flow diversion treatment of cerebral aneurysms: a multicenter study. J Neurointerv Surg 2019;11:796-800.

7 Joshi KC, Beer-Furlan A, Crowley RW, et al. Transradial approach for neurointerventions: a systematic review of the literature. J Neurointerv Surg 2020;12:886-92.

8 He GW, Yang CQ. Characteristics of adrenoceptors in the human radial artery: clinical implications. J Thorac Cardiovasc Surg 1998;115:1136-41.

9 He GW. Verapamil plus nitroglycerin solution maximally preserves endothelial function of the radial artery: comparison with papaverine solution. J Thorac Cardiovasc Surg 1998;115:1321-7.

10 Kiemeneij F, Vajifdar BU, Eccleshall SC, et al. Evaluation of a spasmolytic cocktail to prevent radial artery spasm during coronary procedures. Catheter Cardiovasc Interv 2003:58:281-4.

11 Varenne $\mathrm{O}$, Jégou $\mathrm{A}$, Cohen $\mathrm{R}$, et al. Prevention of arterial spasm during percutaneous coronary interventions through radial artery: the SPASM study. Catheter Cardiovasc Interv 2006;68:231-5.

12 mikailiMirak S, Talasaz AH, Jenab Y, et al. Novel combined topical gel of lidocaineverapamil-nitroglycerin can dilate the radial artery and reduce radial pain during trans-radial angioplasty. Int J Cardiol Heart Vasc 2021;32:100689.

13 Luther E, Chen SH, McCarthy DJ, et al. Implementation of a radial long sheath protocol for radial artery spasm reduces access site conversions in neurointerventions. J Neurointerv Surg 2021;13:547-51.

14 Sandoval Y, Bell MR, Gulati R. Transradial artery access complications. Circ Cardiovasc Interv 2019;12:e007386.

15 Collet C, Corral JM, Cavalcante R, et al. Pressure-mediated versus pharmacologic treatment of radial artery spasm during cardiac catheterisation: a randomised pilot study. EuroIntervention 2017;12:e2212-8.

16 Ying L, Xu K, Gong X, et al. Flow-mediated dilatation to relieve puncture-induced radial artery spasm: a pilot study. Cardiol J 2018;25:1-6.

17 Fitzgerald BM, Babbel LA, Bacomo FK, et al. Regional to the rescue! Axillary brachial plexus nerve block facilitates removal of entrapped transradial catheter placed for cardiac catheterization. Reg Anesth Pain Med 2017;42:475-7.

18 Bhakta P, Zaheer H. Ultrasound-guided radial nerve block to relieve cannulationinduced radial arterial spasm. Can J Anaesth 2017:64:1269-70.

19 Dieter RS, Akef A, Wolff M. Eversion endarterectomy complicating radial artery access for left heart catheterization. Catheter Cardiovasc Interv 2003:58:478-80. 
20 Rashid M, Kwok CS, Pancholy S, et al. Radial artery occlusion after transradial interventions: a systematic review and meta-analysis. J Am Heart Assoc 2016;5. doi:10.1161/JAHA. 115.002686. [Epub ahead of print: 25 Jan 2016].

21 Saito S, Ikei H, Hosokawa $\mathrm{G}$, et al. Influence of the ratio between radial artery inner diameter and sheath outer diameter on radial artery flow after transradial coronary intervention. Catheter Cardiovasc Interv 1999;46:173-8.

22 Dahm JB, Vogelgesang D, Hummel A, et al. A randomized trial of 5 vs. 6 French transradial percutaneous coronary interventions. Catheter Cardiovasc Interv 2002;57:172-6

23 Uhlemann M, Möbius-Winkler S, Mende $\mathrm{M}$, et al. The Leipzig prospective vascular ultrasound registry in radial artery catheterization: impact of sheath size on vascular complications. JACC Cardiovasc Interv 2012;5:36-43.

24 Eid-Lidt G, Rivera Rodríguez A, Jimenez Castellanos J, et al. Distal radial artery approach to prevent radial artery occlusion trial. JACC Cardiovasc Interv 2021;14:378-85.

25 Rao SV, Tremmel JA, Gilchrist IC, et al. Best practices for transradial angiography and intervention: a consensus statement from the Society for Cardiovascular Angiography and Intervention's transradial working group. Catheter Cardiovasc Interv 2014;83:228-36.

26 Kotowycz MA, Dzavík V. Radial artery patency after transradial catheterization. Circ Cardiovasc Interv 2012;5:127-33.

27 Gaudino M, Burzotta F, Bakaeen F, et al. The radial artery for percutaneous coronary procedures or surgery? J Am Coll Cardiol 2018;71:1167-75.

28 Roh SW, Ahn JS, Sung HY, et al. Extracranial-intracranial bypass surgery using a radial artery interposition graft for cerebrovascular diseases. J Korean Neurosurg Soc 2011:50:185-90.

29 Majmundar N, Wilkinson DA, Catapano JS, et al. Reaccessing an occluded radial artery for neuroendovascular procedures: techniques and complication avoidance. J Neurointerv Surg 2020. doi:10.1136/neurintsurg-2020-016758. [Epub ahead of print: 10 Dec 2020].

30 Balaban Y, Elevli MG. It is both possible and safe to perform coronary angiography through the same radial artery, after retrograde recanalization of radial artery occlusion, following a previous coronary angiography. J Interv Cardiol 2018;31:957-63.

31 Schulte-Hermes M, Klein-Wiele 0, Vorpahl M, et al. Feasibility of transradial access for coronary interventions via percutaneous angioplasty of the radial artery in cases of functional radial occlusion. J Invasive Cardiol 2018:30:355-9.

32 Ali S, Abdullah MS, Abdelrahman K, et al. Total radial artery occlusion following transradial access: complete recanalization via the anatomical snuffbox. Methodist Debakey Cardiovasc J 2020;16:314-7.

33 Ayyaz UI Haq M, Rashid M, Gilchrist IC, et al. Incidence and clinical course of limb dysfunction post cardiac catheterization - a systematic review. Circ $J$ 2018;82:2736-44.

34 Ul Haq MA, Rashid M, Kwok CS, et al. Hand dysfunction after transradial artery catheterization for coronary procedures. World J Cardiol 2017;9:609-19.

35 Bertrand OF, Rao SV, Pancholy S. Transradial approach for coronary angiography and interventions: results of the first international transradial practice survey. JACC Cardiovasc Interv 2010:3:1022-31.

36 Hadad MJ, Puvanesarajah V, Deune EG. Complications of transradial catheterization and cannulation. J Hand Surg Am 2019:44:973-9.

37 Hahalis G, Aznaouridis K, Tsigkas G, et al. Radial Artery and Ulnar Artery Occlusions Following Coronary Procedures and the Impact of Anticoagulation: ARTEMIS (Radial and Ulnar ARTEry Occlusion Meta-Analys/S) Systematic Review and Meta-Analysis. J Am Heart Assoc 2017;6. doi:10.1161/JAHA.116.005430. [Epub ahead of print: 23 Aug 2017].

38 Pancholy S, Coppola J, Patel T, et al. Prevention of radial artery occlusion-patent hemostasis evaluation trial (PROPHET study): a randomized comparison of traditional versus patency documented hemostasis after transradial catheterization. Catheter Cardiovasc Interv 2008:72:335-40.

39 Koutouzis MJ, Maniotis CD, Avdikos G, et al. Ulnar artery transient compression facilitating radial artery patent hemostasis (ULTRA): a novel technique to reduce radial artery occlusion after Transradial coronary catheterization. J Invasive Cardiol 2016:28:451-4.

40 Pancholy SB, Bernat I, Bertrand OF, et al. Prevention of radial artery occlusion after transradial catheterization: the PROPHET-II randomized trial. JACC Cardiovasc Interv 2016:9:1992-9.

41 Ghuran AV, Dixon G, Holmberg S, et al. Transradial coronary intervention without prescreening for a dual palmar blood supply. Int J Cardiol 2007;121:320-2.

42 Jolly SS, Yusuf S, Cairns J, et al. Radial versus femoral access for coronary angiography and intervention in patients with acute coronary syndromes (RIVAL): a randomised parallel group, multicentre trial. Lancet 2011;377:1409-20.

43 Zankl AR, Andrassy M, Volz C, et al. Radial artery thrombosis following transradial coronary angiography: incidence and rationale for treatment of symptomatic patients with low-molecular-weight heparins. Clin Res Cardiol 2010;99:841-7.

44 Shroff A, Siddiqui S, Burg A, et al. Identification and management of complications of transradial procedures. Curr Cardiol Rep 2013;15:350.
45 Rhyne D, Mann T. Hand ischemia resulting from a transradial intervention: successful management with radial artery angioplasty. Catheter Cardiovasc Interv 2010;76:383-6.

46 Petroglou D, Didagelos M, Chalikias G, et al. Manual versus mechanical compression of the radial artery after transradial coronary angiography: the MEMORY multicenter randomized trial. JACC Cardiovasc Interv 2018;11:1050-8.

47 Santos SMdos, Rabelo-Silva ER, Aliti GB. Two HEmostasis Methods After Transradlal Catheterization: THEMATIC - protocol for a randomized clinical trial. Rev Gaúcha Enferm 2018;39:e20170257.

48 Sanghvi KA, Montgomery M, Varghese V. Effect of hemostatic device on radial artery occlusion: a randomized comparison of compression devices in the radial hemostasis study. Cardiovasc Revasc Med 2018;19:934-8.

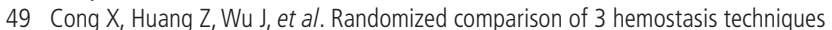
after transradial coronary intervention. J Cardiovasc Nurs 2016;31:445-51.

50 Roberts JS, Niu J, Pastor-Cervantes JA. Comparison of hemostasis times with a kaolin-based hemostatic pad (QuikClot radial) vs mechanical compression (TR band) following transradial access: a pilot prospective study. J Invasive Cardiol 2017;29:328-34.

51 Roberts JS, Niu J, Pastor-Cervantes JA. Comparison of hemostasis times with a Chitosan-based hemostatic pad (Clo-SurPlus ${ }^{\text {Plus }}$ Radial $^{\mathrm{TM}}$ ) vs mechanical compression (TR Band $($ ) following transradial access: a pilot study. Cardiovasc Revasc Med 2019:20:871-4.

52 Seto AH, Rollefson W, Patel MP, et al. Radial haemostasis is facilitated with a potassium ferrate haemostatic patch: the Statseal with TR band assessment trial (STAT). Eurolntervention 2018;14:e1236-42

53 Dai N, Xu D-chun, Hou L, et al. A comparison of 2 devices for radial artery hemostasis after transradial coronary intervention. J Cardiovasc Nurs 2015;30:192-6.

54 Kang S-H, Han D, Kim S, et al. Hemostasis pad combined with compression device after transradial coronary procedures: a randomized controlled trial. PLoS One 2017:12:e0181099

55 Safirstein JG, Elfandi A, Reid N, et al. Randomized trial of radial hemostasis using focused vs balloon compression devices. J Invasive Cardiol 2020;32:169-74.

56 Barrette L-X, Vance AZ, Shamimi-Noori S, et al. Nonfemoral arterial hemostasis following percutaneous intervention using a focused compression device. Cardiovasc Intervent Radiol 2020:43:714-20.

57 Minor RL, Maley T, Jenkins D, et al. Randomized trial of VasoStat versus TR band following radial artery access for catheterization procedures. J Invasive Cardiol 2021;33:E84-90

58 Fernandez RS, Lee A. Effects of methods used to achieve hemostasis on radial artery occlusion following percutaneous coronary procedures: a systematic review. JBI Database System Rev Implement Rep 2017:15:738-64.

59 Goel S, Cordeiro N, Friedman M. Radial artery perforation complicating percutaneous coronary intervention. Cardiovasc Revasc Med 2019;20:26-7.

60 Calviño-Santos RA, Vázquez-Rodríguez JM, Salgado-Fernández J, et al. Management of iatrogenic radial artery perforation. Catheter Cardiovasc Interv 2004;61:74-8

61 Chatterjee A, White JS, Leesar MA. Management of radial artery perforation during transradial catheterization using a polytetrafluoroethylene-covered coronary stent. Cardiovasc Revasc Med 2017;18:133-5

62 Bertrand OF. Acute forearm muscle swelling post transradial catheterization and compartment syndrome: prevention is better than treatment! Catheter Cardiovasc Interv 2010;75:366-8.

63 Tizon-Marcos H, Barbeau GR. Incidence of compartment syndrome of the arm in a large series of transradial approach for coronary procedures. J Interv Cardiol 2008:21:380-4

64 Lee Y-K, Lee S-H, Kwon T-Y. Acute compartment syndrome of the forearm associated with transradial coronary intervention. J Hand Surg Eur Vol 2020;45:1753193419899007:852-6

65 Friedrich JB, Shin AY. Management of forearm compartment syndrome. Hand Clin 2007;23:245-54. vii.

66 Sanmartín M, Cuevas D, Goicolea J, et al. Vascular complications associated with radial artery access for cardiac catheterization. Revista Española de Cardiología 2004:57:581-4.

67 Collins N, Wainstein R, Ward M, et al. Pseudoaneurysm after transradial cardiac catheterization: case series and review of the literature. Catheter Cardiovasc Interv 2012:80:283-7.

68 Saririan M, Pyne CT. Sterile granuloma formation following radial artery catheterization: too many cooKs? Catheter Cardiovasc Interv 2010;76:907-8. author reply $909-10$

69 Zellner C, Ports TA, Yeghiazarians Y, et al. Sterile radial artery granuloma after transradial procedures: a unique and avoidable complication. Catheter Cardiovasc Interv 2010;76:673-6.

70 Aoun J, Hattar L, Dgayli K, et al. Update on complications and their management during transradial cardiac catheterization. Expert Rev Cardiovasc Ther 2019:17:741-51.

71 Almallouhi E, Al Kasab S, Sattur MG, et al. Incorporation of transradial approach in neuroendovascular procedures: defining benchmarks for rates of complications and conversion to femoral access. J Neurointerv Surg 2020;12:1122-6. 
72 Chen SH, Brunet M-C, Sur S, et al. Feasibility of repeat transradial access for neuroendovascular procedures. J Neurointerv Surg 2020;12:431-4.

73 Hanaoka Y, Koyama J-I, Ogiwara T, et al. Feasibility and safety of radialfirst approach with a radial-specific neurointerventional guiding sheath for intracranial aneurysm coiling in the anterior circulation. World Neurosurg 2020;142:e297-306.

74 Hanaoka Y, Koyama J-I, Yamazaki D, et al. Transradial approach as the primary vascular access with a 6 - Fr Simmons guiding sheath for anterior circulation interventions: a single-center case series of 130 consecutive patients. World Neurosurg 2020;138:e597-606.

75 Jaroenngarmsamer T, Bhatia KD, Kortman $\mathrm{H}$, et al. Procedural success with radial access for carotid artery stenting: systematic review and meta-analysis. J Neurointerv Surg 2020;12:87-93

76 Peterson C, Waldau B. Transradial access for thrombectomy in acute stroke: a systematic review and meta-analysis. Clin Neurol Neurosurg 2020;198:106235.

77 Pons RB, Caamaño IR, Chirife OS, et al. Transradial access for diagnostic angiography and interventional neuroradiology procedures: a four-year single-center experience. Interv Neuroradiol 2020;26:506-13.

78 Snelling BM, Sur S, Shah SS, et al. Transradial cerebral angiography: techniques and outcomes. J Neurointerv Surg 2018;10:874-81.

79 Goldman DT, Bageac D, Mills A, et al. Transradial approach for neuroendovascular procedures: a single-center review of safety and feasibility. AJNR Am J Neuroradiol 2021;42:313-8.
80 Vergara-Garcia D, Gomez-Paz S, Robinson TM, et al. Transition to radial approach for neurovascular procedures is safe and convenient: characterization of a learning experience. Oper Neurosurg (Hagerstown) 2020;19:489-94.

81 Sattur MG, Almallouhi E, Lena JR, et al. Illustrated guide to the transradial approach for neuroendovascular surgery: a step-by-step description gleaned from over 500 cases at an early Adopter single center. Oper Neurosurg (Hagerstown) 2020;19:181-9.

82 Catapano JS, Fredrickson VL, Fujii T, et al. Complications of femoral versus radial access in neuroendovascular procedures with propensity adjustment. J Neurointerv Surg 2020;12:611-5.

83 Li Y, Chen SH, Spiotta AM, et al. Lower complication rates associated with transradial versus transfemoral flow diverting stent placement. I Neurointerv Surg 2021;13:91-5.

84 Phillips TJ, Crockett MT, Selkirk GD, et al. Transradial versus transfemoral access for anterior circulation mechanical thrombectomy: analysis of 375 consecutive cases Stroke Vasc Neurol;17:svn-2020-000624.

85 Al Saiegh F, Sweid A, Chalouhi N. Comparison of transradial vs Transfemoral access in neurovascular fellowship training: overcoming the learning curve. Oper Neurosurg 2021;21:3-7.

86 Catapano JS, Ducruet AF, Nguyen CL, et al. Propensity-adjusted comparative analysis of radial versus femoral access for neurointerventional treatments. Neurosurgery 2021;88:E505-9.

87 Valgimigli M, Gagnor A, Calabró P, et al. Radial versus femoral access in patients with acute coronary syndromes undergoing invasive management: a randomised multicentre trial. Lancet 2015:385:2465-76. 